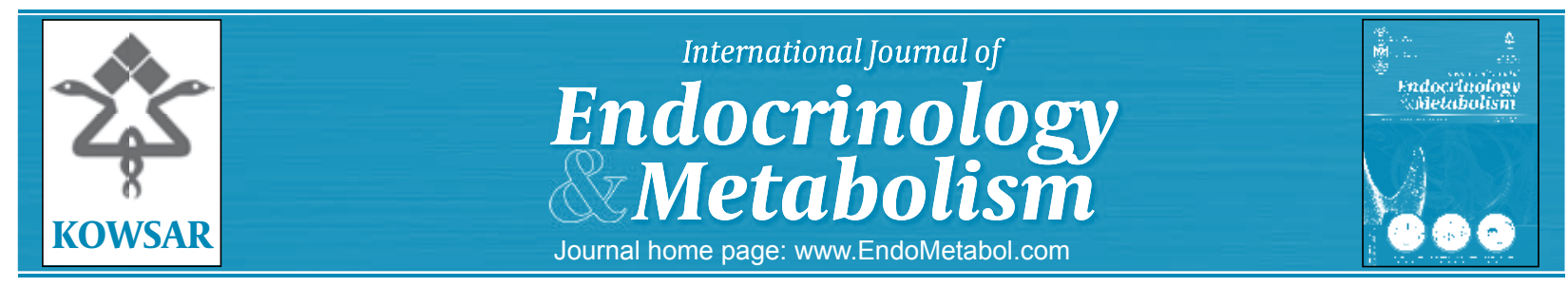

\title{
Body Mass Index and Periodontal Health are Correlated in Postmenopausal Women With Low Bone Density
}

\author{
Leena Palomo ${ }^{1 *}$, Maria Clarinda Buenocamino ${ }^{2}$, Holly Thacker ${ }^{3}$ \\ ${ }^{1}$ Department of Periodontics, School of Dental Medicine, Western Reserve University, Cleveland, OH, USA \\ ${ }^{2}$ Department of Internal Medicine and Center for Specialized Women's Health, Cleveland Clinic, Cleveland, OH, USA \\ ${ }^{3}$ Center for Specialized Women's Health, Cleveland Clinic, Cleveland, OH, USA
}

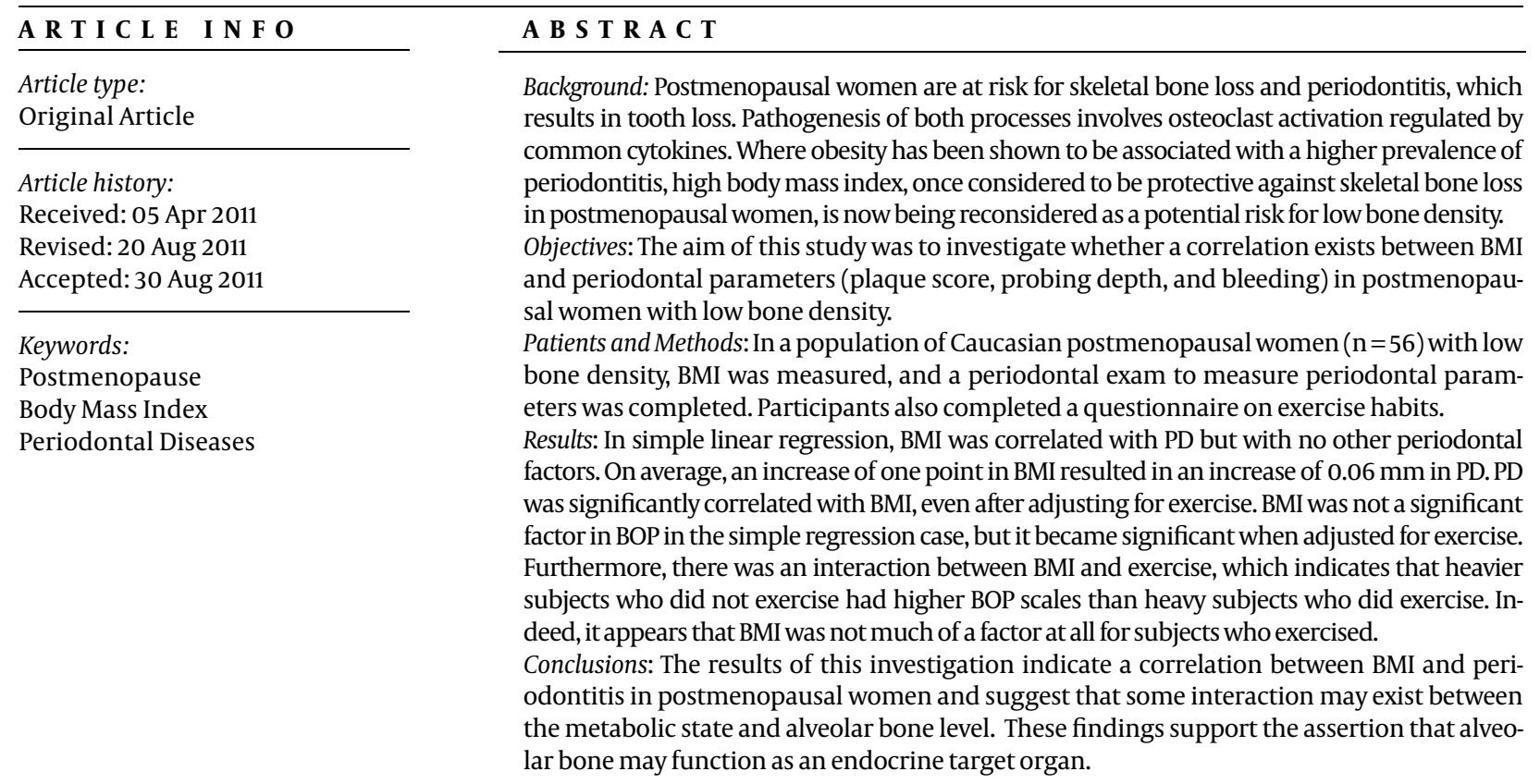

Copyright $\odot 2011$ Kowsar M. P. Co. All rights reserved.

- Implication for health policy/practice/research/medical education:

This study has clinical application as it offers support for the inclusion of periodontal diagnosis and treatment programs for PMW as part of their menopause-care regimen.

- Please cite this paper as:

Palomo L, Buenocamino MC, Thacker H. Body Mass Index (BMI) and Periodontal Health are Correlated in Postmenopausal Women With Low Bone Density. Int J Endocrinol Metab. 2011;9(4):364-8. DOI: 10.5812/Kowsar.1726913X.2617

\section{Background}

As increasing evidence suggests that skeletal bone may be an endocrine target organ, high body mass index

* Corresponding author: Leena Palomo, Department of Periodontics, School of Dental Medicine, Case, Western Reserve University, 2124 Cornell Rd, Cleveland, OH 44106, USA. Tel:+1-2163686300, Fax:+1-2163683266, E-mail: leena.palomo@case.edu

DOI:10.5812/Kowsar.1726913X.2617

Copyright $\odot 2011$ Kowsar M.P.Co. All rights reserved.
(BMI), once considered to be protective against skeletal bone loss in postmenopausal women (PMW), is now being reconsidered as a potential risk for low bone density (1-3). PMW are at risk for not only skeletal but also alveolar bone loss from periodontitis and subsequent tooth loss (4). Although alveolar bone loss from periodontitis is triggered by plaque bacterial biofilm, a consequence of poor oral hygiene, both conditions involve the same cytokine mediators in a cascade ending in osteoclast activa- 
tion. These proinflammatory cytokines have been shown to be upregulated by adipokines and leptin, which are released by adipocytes (5). Like the postmenopause state, obesity is also a risk for periodontitis (6-15). In a cohort of PMW with low bone density, a relationship between BMI and periodontitis would suggest an interaction between metabolic state and bone level and support the assertion that alveolar bone functions as an endocrine target organ. Periodontitis and postmenopausal osteoporosis both appear to benefit from exercise as well (16-20), suggesting that exercise plays a role in the pathogenesis of both conditions. There is no evidence on the relationship between BMI and periodontal health in postmenopausal women with low bone density.

\section{Objectives}

The aim of this study was to investigate whether a correlation existed between BMI and periodontal parameters (plaque score, probing depth, and bleeding) in postmenopausal women with low bone density. An ad hoc analysis of the role of exercise in this relationship was also completed.

\section{Patients and Methods}

\subsection{Ethical Approval Summary}

This study was reviewed and approved by the Investigational Review Board (IRB) of Case Western Reserve University and the Cleveland Clinic for compliance with current ethical considerations. All subjects associated with this project were treated in an ethical manner and in accordance with the Belmont Report. Additionally, the investigators complied with all applicable federal, state, and local regulations that related to the protection of human subjects, including regulations from the Food and Drug Administration and the Department of Health and Human Services. Finally, the study protocol conforms to the ethical guidelines of the 1975 Declaration of Helsinki as reflected in an a priori approval by the IRB.

\subsection{Informed Consent}

Informed consent procedures were approved by the IRB of Case Western Reserve University and the Cleveland Clinic. Detailed information related to the study was provided during the interview when informed consent was obtained, and all participant questions were answered. Eligible participants were asked to complete a screening and study questionnaires and then were scheduled for a comprehensive dental examination only after obtaining approved consent.

\subsection{Participant Privacy and Confidentiality}

All participants were informed of the interview process in a private area. After giving their consent, they were interviewed. All dental examinations were conducted in private examination rooms. All records, documents, laboratory results, and case-report forms were kept confidential. Record access was limited to the principal investigator and coinves- tigators as specified in the Health Insurance Portability and Accountability Act authorization.

\subsection{Blinding and Personnel Training}

The accuracy and reliability of the clinical measurements taken by the principal investigator were established prior to data collection. Five patients were recruited from the records of the Graduate Periodontal Clinic of Case School of Dental Medicine for two sessions of periodontal examination by two periodontists. Blind comprehensive examinations were performed by both examiners. A second, repeat examination was performed a week later by the principal investigator. A statistical analysis was then performed to verify interexaminer and intraexaminer reliability (all $r$ values $>0.92$ ) The principal investigator was, thereby, shown to be accurate and reliable prior to data collection.

\subsection{Patient Selection}

Patients of the Center for Specialized Women's Health (a center comprising multidisciplinary health professionals including women's health specialists, gynecologists, ISCDcertified bone densitometrists, and endocrinologists who focus on women's health) at the Cleveland Clinic, Cleveland $\mathrm{OH}$ were randomly asked to participate. Volunteers were screened for participation based on the following inclusion criteria: they had to be ambulatory, postmenopausal (either surgically or naturally), and Caucasian and have low bone density and an oral hygiene score better than $80 \%$ for sites free of plaque. Low bone density was established using a DEXA test. In accordance with the WHO definition for low bone density, the threshold for inclusion was set at $t$-scores $\leq$ -2.0 at either the hip or spine. The study used two exclusion criteria. The first comprised all of the risk factors for alveolar bone loss established by the American Academy of Periodontology, including smoking, acute dental abscess or trauma, diabetes mellitus, immunosuppression, leukemia, neutropenia, renal failure, agranulocytosis, scleroderma, Sjogren's syndrome, and cancer treatment (surgery, radiation, or chemotherapy). Second, participants were excluded if they had used any of the following medications in the previous 5 years: Cyclosporine, Estrogen, Nifedipine, Phenytoin, systemic steroids (oral or parenteral equivalent to Prednisone 5 mg daily for more than 3 months), or Teriparatide. Characteristics of the study participants who met the inclusion criteria are described in Table 1.

\begin{tabular}{llll}
\hline \multicolumn{4}{l}{ Table 1. Characteristics of the Total Study Population } \\
\hline Factor & Mean & SD $^{\mathbf{a}}$ & Median \\
\hline Age, $\mathrm{y}$ & 63 & 5.1 & 62 \\
Weight, $\mathrm{kg}$ & 64.9 & 11.8 & 63.4 \\
Height, $\mathrm{m}$ & 1.6 & 0.1 & 1.6 \\
BMI $^{\mathrm{a}}, \mathrm{kg} / \mathrm{m}^{2}$ & 24.6 & 4.2 & 24 \\
T-score spine & -1.8 & 0.9 & -2 \\
T-score hip & -1.9 & 0.8 & -2 \\
\hline a Abbreviations: BMI Body mass index; SD, Standard deviation
\end{tabular}




\subsection{Data Collection}

Periodontal examinations were completed for all participants to evaluate periodontal health. The data collected included standard periodontal parameters: periodontal probing depth (PD), bleeding on probing (BOP), gingival recession (CEJ) and plaque score (PS). PS was the ratio of biofilm-plaque-covered sites in the dentition to the total number of surfaces (21). The measurement of the primary etiologic agent for periodontitis was bacterial-plaque biofilm. Structural breakdown of the periodontium was dependent on inflammation; BOP (measured as an index) was used to assess inflammation $(22,23)$; PD (measured in millimeters) was the depth of the pocket area between the tooth and the attachment of gingival soft tissue and was a proxy measurement of periodontal disease severity. In general, the greater the PD, the greater the attachment loss around a tooth. Therefore, the greater the PD, the more severe the disease. PD was measured at six sites per tooth. CEJ (measured in millimeters) was the soft tissue recession at the midfacial and midlingual tooth surfaces. CEJ is a component of the overall attachment loss and was used to determine the extent and severity of periodontitis. Height and weight were used to calculate BMI. Although not the primary study objective, pilot assessment of physical exercise was completed in an ad hoc analysis using a

\section{Probing Depth}

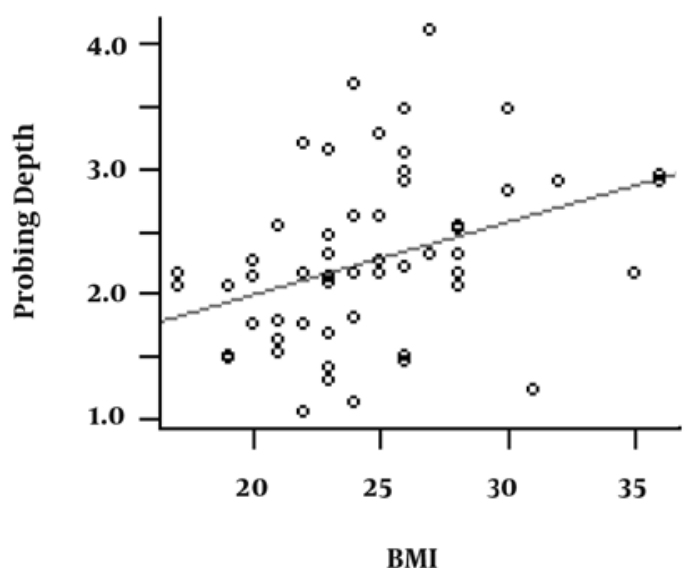

Figure 1. Probing Depth survey questionnaire. All participants were asked whether they met the criteria for exercise set forth by the National Osteoporosis Foundation. This criteria included cardiovascular exercise at least 5 times a week for 30-40 minutes per session and weight exercises at least twice a week. If the participant answered "yes" to all criteria listed on the questionnaire, he or she was considered to meet the exercise requirement.

\subsection{Data Analysis}

A simple linear regression analysis was performed to identify the relationships between BMI and PD and between BMI and BOP. A simple linear regression was performed again when adjusting for exercise. The threshold for correlation significance was set at $P=0.05$.

\section{Results}

In a simple linear regression, BMI was correlated with PD. On average, an increase of one point in BMI resulted in an increase of $0.06 \mathrm{~mm}$ in PD (Figure 1). At least one periodontal defect was found in 54 (96\%) of the 56 participants. Seven participants (12.5\%) had a BMI under 20, 42 (75\%) had a BMI between 21 and 29, and 7 (12\%) had a BMI over 30. Mean PD was 1.8, 2.4, and 2.6, respectively. (Table 2) PD was significantly correlated with BMI $(P<0.05)$,

\section{Bleeding on Probing}

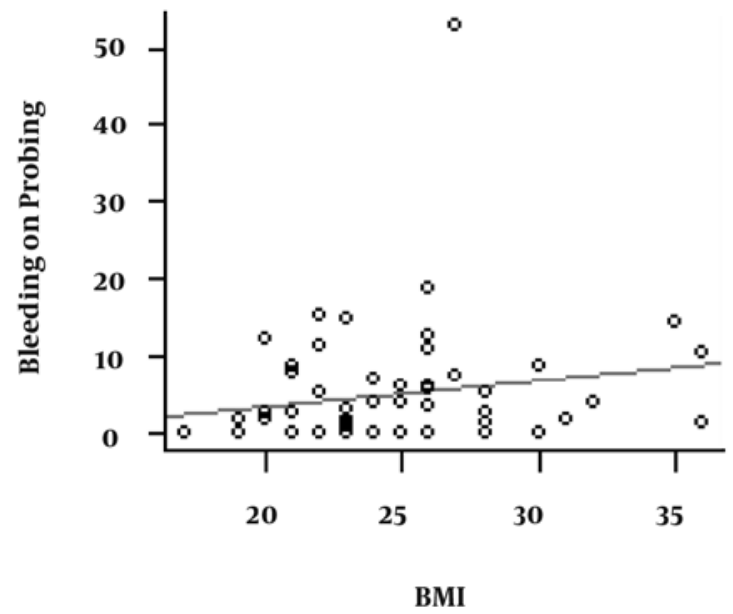

Figure 2. Bleeding on Probing

\begin{tabular}{|c|c|c|c|c|c|c|c|}
\hline \multirow[b]{3}{*}{ Plaque score } & \multicolumn{3}{|c|}{ Correlation $^{a}$} & \multicolumn{4}{|c|}{ Regression Coefficient $^{a}$} \\
\hline & \multirow{2}{*}{$\begin{array}{l}r \\
-0.26\end{array}$} & \multicolumn{2}{|c|}{ 95\% Confidence Interval } & \multirow{2}{*}{$\begin{array}{l}\text { Beta } \\
0.97\end{array}$} & \multicolumn{2}{|c|}{ 95\% Confidence Interval } & \multirow{2}{*}{$\begin{array}{l}P \text { value } \\
0.08\end{array}$} \\
\hline & & -0.52 & 0.03 & & 0.93 & 1.02 & \\
\hline Probing depth & 0.36 & 0.1 & 0.57 & 0.06 & 0.02 & 0.1 & 0.007 \\
\hline Bleeding on probing & 0.18 & -0.09 & 0.42 & 0.35 & -0.17 & 0.86 & 0.18 \\
\hline CEJ & -0.05 & -0.31 & 0.22 & -0.01 & -0.09 & 0.07 & 0.73 \\
\hline
\end{tabular}

${ }^{a}$ Response was subject to a logarithmic transformation 


\begin{tabular}{|c|c|c|c|c|}
\hline & Level & Beta & 95\% Confidence Interval & Pvalue \\
\hline Intercept & & 1.15 & $(-0.01,2.32)$ & 0.052 \\
\hline BMI & & 0.06 & $(0.02,0.10)$ & 0.008 \\
\hline Exercise & Yes vs. No & -0.31 & $(-0.86,0.25)$ & 0.28 \\
\hline
\end{tabular}

even after adjusting for exercise. BMI was not a significant factor in BOP in the unadjusted simple regression analysis, but BMI becomes significant when the model was adjusted for exercise. Furthermore, there was an interaction between BMI and exercise, which indicated that heavy subjects who did not exercise had higher BOP scores than heavy subjects who did. (Figure 2) Indeed, it appears that BMI was not much of a factor at all for subjects who exercised (Table 3).

\section{Discussion}

Mapping periodontal parameters across BMI in PMW with low bone density reveals that BMI significantly correlates with PD. In other words, after excluding confounders, the higher the BMI, the more severe the periodontitis. This finding in PMW with low bone density is consistent with reports that obesity was associated with periodontitis in the overall population (24). Because Caucasian PMW are at great risk for low bone density, this study focused on that cohort. Studies focusing on other races are needed to more fully explain the correlation between BMI and periodontal parameters. Elucidating the mechanism responsible for the correlation between BMI and periodontal parameters is beyond the scope of this study; however, based on the findings, bone cells, proinflammatory cytokines, adipokines, and leptin, which play a role in both weight control, glucose regulation, alveolar bone loss in periodontitis, and skeletal bone loss in postmenopausal osteoporosis, warrant further investigation.(25-34). When mapping BOP, a measure of periodontal inflammation, BMI became a significant factor only when adjusted for exercise. This finding is consistent with previous investigations showing a reduction of inflammatory biomarkers, adipokines and CRP, and cytokines in overweight women who exercise (35). The results revealed an interaction between BMI and exercise, which indicated that heavy subjects who did not exercise had higher levels of periodontal inflammation than heavy subjects who did. Presumably, this reduction in the overall inflammatory state had more to do with exercise than BMI alone. However, the BMI measurement did not take into consideration fractions of lean muscle mass versus fat. Therefore, the pathophysiological role of adipose tissue, particularly as a source of adipokines and leptin versus lean muscle mass in skeletal homeostasis, cannot be understood from this study. The findings of the current investigation warrant future investigations with a larger sample size comparison of periodontal parameters in PMW with low bone density who exercise versus those who do not. The findings of this study support the inclusion of periodontal diagnosis and treatment programs for PMW as part of their menopause-care regimen (36).

The results of this investigation indicate a significant correlation between BMI and periodontitis in PMW. An increase of one point in BMI resulted in an increase of $0.06 \mathrm{~mm}$ in PD. This correlation suggests some interaction between the metabolic state and alveolar bone level. These results support the assertion that bone may be an endocrine target organ.

\section{Acknowledgements}

None declared.

\section{Financial Disclosure}

None declared.

\section{Funding/Support}

Clinical and Translational Science Collaborative at Cleveland Clinic Foundation Cleveland $\mathrm{OH}$.

\section{References}

1. Migliaccio S, Greco EA, Fornari R, Donini LM, Lenzi A. Is obesity in women protective against osteoporosis? Diabetes Metab Syndr Obes. 2011;4:273-82.

2. Jeon YK, Lee JG, Kim SS, Kim BH, Kim SJ, Kim YK, et al. Association between bone mineral density and metabolic syndrome in preand postmenopausal women. Endocr J. 2011;58(2):87-93.

3. Hwang DK, Choi HJ. The relationship between low bone mass and metabolic syndrome in Korean women. Osteoporos Int. 2010;21(3):425-31.

4. Koh JM, Khang YH, Jung CH, Bae S, Kim DJ, Chung YE, et al. Higher circulating hsCRP levels are associated with lower bone mineral density in healthy pre- and postmenopausal women: evidence for a link between systemic inflammation and osteoporosis. Osteoporos Int. 2005;16(10):1263-71.

5. Drozdzowska B, Pluskiewicz W, Michno M. Tooth count in elderly women in relation to their skeletal status. Maturitas. 2006;55(2):126-31.

6. Dalla Vecchia CF, Susin C, Rosing CK, Oppermann RV, Albandar JM. Overweight and obesity as risk indicators for periodontitis in adults. J Periodontol. 2005;76(10):1721-8.

7. Bawadi HA, Khader YS, Haroun TF, Al-Omari M, Tayyem RF. The association between periodontal disease, physical activity and healthy diet among adults in Jordan. J Periodontal Res. 2011;46(1):74-81.

8. Perlstein MI, Bissada NF. Influence of obesity and hypertension on the severity of periodontitis in rats. Oral Surg Oral Med Oral Pathol.1977;43(5):707-19.

9. Saito T, Shimazaki Y, Koga T, Tsuzuki M, Ohshima A. Relationship between upper body obesity and periodontitis. J Dent Res. 2001;80(7):1631-6.

10. Al-Zahrani MS, Bissada NF, Borawskit EA. Obesity and periodontal disease in young, middle-aged, and older adults. J Periodontol. 2003;74(5):610-5. 
11. Alabdulkarim M, Bissada N, Al-Zahrani M, Ficara A, Siegel B. Alveolar bone loss in obese subjects. J Int Acad Periodontol. 2005;7(2):34-8.

12. Sarlati F, Akhondi N, Ettehad T, Neyestani T, Kamali Z. Relationship between obesity and periodontal status in a sample of young Iranian adults. Int Dent J. 2008;58(1):36-40.

13. Khader YS, Bawadi HA, Haroun TF, Alomari M, Tayyem RF. The association between periodontal disease and obesity among adults in Jordan. J Clin Periodontol. 2009;36(1):18-24.

14. Wood N, Johnson RB. The relationship between smoking history, periodontal screening and recording (PSR) codes and overweight/obesity in a Mississippi dental school population. Oral Health Prev Dent. 2008;6(1):67-74.

15. Rubino F, Gagner M, Gentileschi P, Kini S, Fukuyama S, Feng J, et al. The early effect of the Roux-en-Y gastric bypass on hormones involved in body weight regulation and glucose metabolism. Ann Surg. 2004;240(2):236-42.

16. Al-Zahrani MS, Borawski EA, Bissada NF. Increased physical activity reduces prevalence of periodontitis. J Dent. 2005;33(9):703-10.

17. Campbell PT, Campbell KL, Wener MH, Wood BL, Potter JD, McTiernan A, et al. A yearlong exercise intervention decreases CRP among obese postmenopausal women. Med Sci Sports Exerc. 2009;41(8):1533-9.

18. Frank LL, Sorensen BE, Yasui Y, Tworoger SS, Schwartz RS, Ulrich $\mathrm{CM}$, et al. Effects of exercise on metabolic risk variables in overweight postmenopausal women: a randomized clinical trial. Obes Res. 2005;13(3):615-25.

19. McLeod KM, Johnson CS. A systematic review of osteoporosis health beliefs in adult men and women. $J$ Osteoporos. 2011;2011:197454

20. Premaor MO, Pilbrow L, Tonkin C, Parker RA, Compston J. Obesity and fractures in postmenopausal women.J Bone Miner Res. 2010;25(2):292-7.

21. O'Leary T], Drake RB, Naylor JE. The plaque control record. J Periodontol. 1972;43(1):38.

22. Loe H, Silness J. Periodontal Disease in Pregnancy. I. Prevalence and Severity. Acta Odontol Scand.1963;21:533-51.

23. Silness J, Loe H. Periodontal Disease in Pregnancy. Ii. Correlation between Oral Hygiene and Periodontal Condtion. Acta Odontol Scand. 1964;22:121-35.
24. Pataro AL, Costa FO, Cortelli SC, Cortelli JR, Abreu MH, Costa JE. Association between severity of body mass index and periodontal condition in women. Clin Oral Investig. 2011.

25. Gomez-Ambrosi J, Rodriguez A, Catalan V, Fruhbeck G. The bone-adipose axis in obesity and weight loss. Obes Surg. 2008;18(9):1134-43.

26. Takeda S. [Effect of obesity on bone metabolism]. Clin Calcium. 2008;18(5):632-7.

27. Gimble JM, Zvonic S, Floyd ZE, Kassem M, Nuttall ME. Playing with bone and fat.J Cell Biochem. 2006;98(2):251-66.

28. Riesco E, Choquette S, Audet M, Lebon J, Tessier D, Dionne IJ. Ef fect of exercise training combined with phytoestrogens on adipokines and C-reactive protein in postmenopausal women: a randomized trial. Metabolism. 2011.

29. Genco RJ, Grossi SG, Ho A, Nishimura F, Murayama Y. A proposed model linking inflammation to obesity, diabetes, and periodontal infections. J Periodontol. 2005;76(Suppl 11):2075-84

30. Fisher G, Hyatt TC, Hunter GR, Oster RA, Desmond RA, Gower BA Effect of diet with and without exercise training on markers of inflammation and fat distribution in overweight women. Obesity (Silver Spring). 2011;19(6):1131-6.

31. Shimada Y, Komatsu Y, Ikezawa-Suzuki I, Tai H, Sugita N, Yoshie $H$. The effect of periodontal treatment on serum leptin, interleukin-6, and C-reactive protein. J Periodontol.2010;81(8):1118-23.

32. Santos-Alvarez J, Goberna R, Sanchez-Margalet V. Human leptin stimulates proliferation and activation of human circulating monocytes. Cell Immunol.1999;194(1):6-11.

33. Hwa IJ, Fawzi AB, Graziano MP, Ghibaudi L, Williams P, Van Heek $\mathrm{M}$, et al. Leptin increases energy expenditure and selectively promotes fat metabolism in ob/ob mice. Am J Physiol. 1997;272(4 Pt 2):R1204-9.

34. Pelleymounter MA, Cullen MJ, Baker MB, Hecht R, Winters D, Boone T, et al. Effects of the obese gene product on body weight regulation in ob/ob mice. Science. 1995;269(5223):540-3.

35. Ryan AS, Nicklas BJ. Reductions in plasma cytokine levels with weight loss improve insulin sensitivity in overweight and obese postmenopausal women. Diabetes Care. 2004;27(7):1699-705.

36. Buencamino MC, Palomo L, Thacker HL. How menopause affects oral health, and what we can do about it. Cleve Clin J Med. 2009;76(8):467-75. 